\title{
SIGHTING OF A BAND-TAILED PIGEON AT MEDICINE HAT
}

SIG JORDHEIM, Kyle, SK

On May 8, 1998 I took my wife Ruby to Medicine Hat. Sunday was Mothers Day, and our son Cameron, who lives in Medicine Hat, wished to give her a present of her own choosing.

Cameron has a house there that overlooks the South Saskatchewan River. Saturday morning, we were sitting on the balcony enjoying the view, when I noted a medium size bird fly over the house and land on a treetop a block away. The bird, after a short look around began eating, presumably the cottonwood seed heads.

This bird was very pigeon-like in flight and shape, but was doing something unusual for a Rock Dove. I had seen a Band-tailed Pigeon on my farm near Kyle, Saskatchewan for three days in
1988. I wondered if this bird was the same species. Through binoculars, I noted the yellow bill and the white ring on the neck, but as it was facing us it was not possible to see the band on the tail. We notified the Interpretation Centre at Police Point and found that the Bandtailed Pigeon was not on the bird list for Medicine Hat and had not been identified there.

The bird stayed in the same tree all day, Saturday, spending much time resting, was gone for a brief period Sunday morning but soon returned to that particular tree. I phoned Jo Anne Reynolds, Treasurer and Co-Editor of the Grasslands Naturalists. I understand that she was able to see the bird, later that day, after we had left for Saskatchewan.

Our task in North America is more demanding than in England, where fewer than 70 species of butterflies occur; much less so than in Costa Rica, where some 2,000 species fly.

We have something under 700 species, about the same number as North American birds. 